\title{
Relationships between hormonal parameters, body fat distribution and bone mineral density in women with psychogenic functional hypothalamic amenorrhea
}

\author{
Justyna Syrenicz ${ }^{1}$, Mariola Krzyscin², ${ }^{-1}$, Elzbieta Sowinska-Przepiera²(1) \\ ${ }^{1}$ Department of Diabetology and Internal Medicine, Pomeranian Medical University, Poland \\ ${ }^{2}$ Department of Endocrinology, Metabolic and Internal Diseases, Pomeranian Medical University, Szczecin, Poland \\ ${ }^{3}$ Department of Gynecology and Obstetrics, Klinikum Frankfurt (Oder), Frankfurt (Oder), Germany
}

\begin{abstract}
Objectives: Available evidence implies that unfavorable changes in the distribution of adipose tissue resulting from hormonal imbalance associated with ovarian insufficiency might influence bone mineral density (BMD). The purpose of our study was to verify if volumes of visceral (VAT), female (FAT) and android (AAT) body fat as determined by densitometry determined influence BMD in women with functional menstrual disorders, and if these correlates some endocrine factors. Material and methods: We examined 293 women (mean age $26.7 \pm 4.4$ years) who have had psychogenic type of functional hypothalamic secondary amenorrhea for at least three months (mean $5.82 \pm 0.94$ ). A variety of hormonal tests, determination of BMD and both distribution and volume of adipose tissue were performed.

Results: Volume of adipose tissue in all analyzed body regions indicated a positive correlation with $B M D$ in lumbar spine (VAT: $R=0.277$, FAT: $R=0.345$, AAT: $R=0.336$ ) and entire skeleton (VAT: $R=0.453$, FAT: $R=0.527, A A T: R=0.529$ ). BMD in both the lumbar spine and entire skeleton had positive correlation with body mass index ( $R=0.380$ and $R=0.599$, respectively) and free androgen index values $(R=0.150$ and $R=0.279)$. It showed a negative correlation with sex hormone-binding globulin $(R=-0.191$ and $R=-0.326)$. We did not find a parameter that could be an independent predictor of BMD.

Conclusions: Distribution of body fat is only one of numerous determinants of BMD in women with functional menstrual disorders and should not be treated as the only predictor for bone mass deficiency. Determination of adipose tissue distribution in these patients has probably minor clinical impact.
\end{abstract}

Key words: estrogens; visceral fat; subcutaneous fat; amenorrhea; mineralization

Ginekologia Polska 2021; 92, 11: 753-759

\section{INTRODUCTION}

Relatively common reasons for oligo/amenorrhea are related to stress, fatigue and overloading of duties. Such functional amenorrhea is usually a transient condition, and menstrual cycles return to normal after the elimination of stressors and the regeneration of the body [1]. Many previous studies demonstrated that functional hypothalamic amenorrhea (FHA), the common cause of ovarian insufficiency and menstrual disorders, not only contributes to systemic endocrine disruption but also negatively influences bone mineral density (BMD). Due to their anabolic and antiresorptive properties, ovarian estrogens exert positive effects on bone mineralization [2-4]. Similar effects are also produced by androgens and therefore, these hormones become principal endocrine determinant of BMD in women with ovarian insufficiency [5].

Both estrogens and androgens also play a significant role in adipocyte biology, inhibiting activity of the main lipogenic enzyme, lipoprotein lipase. For example, the lack of the inhibitory effect of estrogens on this enzyme explains higher prevalence of obesity in postmenopausal women. Furthermore, due to a relative excess of androgens, women after menopause are also predisposed to preferential accumulation of visceral adipose tissue (VAT) and android (abdominal) 
subcutaneous fat. Such distribution of adipose tissue is an established risk factor of many metabolic disorders, among them metabolic syndrome [6].

Recent evidence suggests that the distribution of body fat may also influence BMD. While accumulation of subcutaneous adipose tissue may predispose to greater bone density $[7,8]$, an inverse relationship likely exists between VAT and BMD: in some studies, women with higher contents of VAT presented with worse qualitative and quantitative bone parameters [8-10]. This implies that BMD is modulated by distribution of adipose tissue across various anatomical regions, rather than by its absolute volume [11].

Taken together, available evidence implies that unfavorable changes in the distribution of adipose tissue that occur during hormonal imbalance associated with ovarian insufficiency might influence BMD. However, to the best of our knowledge, none of previous studies analyzed the whole spectrum of the problem, but rather its selected aspects: influence of ovarian insufficiency on BMD, relationships between sex hormones and adipocyte metabolism, or a link between the distribution of body fat and bone quality.

\section{Objectives}

The aim of this study was to verify if adipose tissue volume, either overall or in various regions (visceral, female and android) exerts an effect on BMD in women with psychogenic functional hypothalamic amenorrhea, and if these relationships correlate with endocrine factors. Detailed objectives of the research were: 1 . analysis of a relationship between adipose tissue volume and BMD; 2 . identification of endocrine parameters showing significant correlations with adipose tissue volume and BMD and 3. an attempt to identify independent predictors of BMD in women with functional menstrual disorders.

\section{MATERIAL AND METHODS \\ Patients}

The study included a group of 293 women between the ages of 16 and 37 years (mean $26.7 \pm 4.4$ ), who were diagnosed and underwent treatment at Department of Endocrinology, Pomeranian Medical University in Szczecin, (Poland) between 2013 and 2017.

To set the diagnosis a thorough personal history was obtained. Among others we asked about menstrual pattern (including information about all previous menstrual cycles since menarche), weight loss, diet, low weight eating disorders, level of physical activity, significant stressors, mental condition, bone fractures in the past, chronic diseases and substance abuse.

The patients satisfied the following inclusion criteria: 1 . at least three months of secondary amenorrhea (mean $5.82 \pm 0.94$ ); 2 . psychological problems (learning and/or family and/or problems at work); 3. lack of major abnormalities on physical exam and 4. Caucasian race.

Upon the basis of medical history, standardized questionnaire survey, gynecological examination and laboratory tests the following exclusion criteria were established: 1. pregnancy; 2 . congenital adrenal hyperplasia; 3 . polycystic ovary syndrome; 4 . low birth weight or preterm birth; 5 . premature ovarian failure; 6. at least one confirmed episode of an eating disorder; 7. episodes of impaired growth and body mass gain; 8. proven psychiatric disease; 9. extensive participation in sports; 10 . metabolic disorders that may be associated with decreased bone mineralization; 11. prolonged use of stimulants or drugs that may affect bone metabolism; and 12. personal and familial history of osteoporosis and bone fracture.

After excluding all endocrinopathies, poor nutrition and eating disorders along with intensive physical exercise, lower socioeconomic status and familial predispositions it was considered that in the studied group of patients there was a psychogenic type of FHA, which is often diagnosed as an exclusionary diagnosis [1].

\section{Ethics}

The protocol of our study was approved by the Bioethics Committee of the Pomeranian Medical University in Szczecin (no. KB-0012/115/15). Written informed consent was obtained from all participants or their legal guardians.

\section{Basic procedures}

At first a detailed medical history was collected, and a physical examination was performed including anthropometric measurements (body weight and body height) following with calculation of body mass index (BMI).

\section{Laboratory tests}

The following endocrine parameters were determined after collecting venous blood form the antecubital vein: luteinizing hormone (LH), follicle-stimulating hormone (FSH), estradiol, thyroid-stimulating hormone (TSH), free triiodothyronine (fT3), free thyroxine (fT4), androstenedione, dehydroepiandrosterone (DHEA), free testosterone and sex hormone-binding 
globulin (SHBG) - used to calculate free androgen index (FAl), 17-hydroxyprogesterone, prolactin at the baseline (PRL $0^{\prime}$ ) and at 60 min of metoclopramide challenge (PRL 60'), adrenocorticotropic hormone (ACTH), cortisol at the baseline and after dexamethasone suppression test. All parameters were determined using conventional methods, electrochemiluminescence immunoassay for: $\mathrm{LH}, \mathrm{FSH}$, estradiol, TSH, fT3, fT4, testosterone, SHBG, cortisol, ACTH, PRL, 17-hydroxyprogesterone and DHEA, and immunoenzymatic assay for androstenedione.

\section{Determination of bone mineral density}

BMD of all participants was obtained for both the lumbar spine (L1-L4) and entire skeleton using dual-energy X-ray absorptiometry (DEXA; GE Lunar Prodigy Advance, Madison, with enCORE software version 8.8 ). The results were described as a total value $\left(\mathrm{g} / \mathrm{cm}^{2}\right)$.

\section{Determination of distribution and volume of body fat}

Quantitative body composition, i.e., overall volume of body fat, volumes of VAT, android and female fat, and fat-free mass, was determined preforming DEXA whole body scan (GE Lunar Prodigy Advance, Madison) using CoreScan ${ }^{\mathrm{TM}}$ H8801CP software packages provided by the producer.

\section{Statistical analysis}

The Shapiro-Wilk test was used for normal distribution of continuous variables. The results are shown as arithmetic means, standard deviations (SD) and medians. Power and direction of relationships between pairs of continuous variables underwent an estimation based on Spearman's correlation (R). Parameters that turned out to be associated with dependent variables statistically significant $(p \leq 0.05)$ or close to statistically significant $(p \leq 0.1)$ (adipose tissue volume in various regions and $\mathrm{BMD}$ ) were taken in multiple linear regression models in aim to find independent predictors of these variables. For calculations Statistica 10 software (StatSoft, USA) was used.

\section{RESULTS}

The characteristics of all 293 women participating in the study are summarized in Table 1.

Volume of adipose tissue in all analyzed body regions showed a positive correlation with BMD in the lumbar spine and entire skeleton, FAl, prolactin at the baseline and TSH, and showed an inverse association with SHBG. Moreover, the volumes of android
Table 1. Statistical characteristics of age, anthropometric and endocrine parameters, bone mineral density and adipose tissue volume in the study subjects

\begin{tabular}{|c|c|c|c|}
\hline Variable & Mean & SD & Median \\
\hline Age [years] & 26.7 & 4.4 & 26 \\
\hline Body height $[\mathrm{cm}]$ & 166.45 & 6.20 & 167 \\
\hline Body weight [kg] & 71.60 & 16.65 & 68 \\
\hline BMI $\left[\mathrm{kg} / \mathrm{m}^{2}\right]$ & 25.88 & 6.13 & 24.11 \\
\hline BMD L2-L4 [g/cm²] & 1.22 & 0.13 & 1.23 \\
\hline BMD total $\left[\mathrm{g} / \mathrm{cm}^{2}\right]$ & 1.20 & 0.40 & 1.19 \\
\hline AAT $\left[\mathrm{cm}^{3}\right]$ & 2252.99 & 1464.42 & 1840 \\
\hline FAT $\left[\mathrm{cm}^{3}\right]$ & 4843.38 & 1843.65 & 4556 \\
\hline Fat overall $\left[\mathrm{cm}^{3}\right]$ & 27195.28 & 12094.72 & 23458 \\
\hline VAT $\left[\mathrm{cm}^{3}\right]$ & 548.04 & 571.71 & 342.5 \\
\hline Androstenedione $[\mathrm{ng} / \mathrm{mL}]$ & 3.98 & 1.92 & 3.7 \\
\hline DHEAS $[\mu \mathrm{g} / \mathrm{mL}]$ & 272.98 & 120.72 & 258.8 \\
\hline Testosterone [ng/mL] & 0.49 & 0.22 & 0.47 \\
\hline SHBG [nmol/L] & 56.67 & 47.86 & 45.2 \\
\hline FAI & 5.44 & 5.18 & 4.12 \\
\hline $\begin{array}{l}\text { 17-hydroxyprogesterone } \\
\text { [ng/mL] }\end{array}$ & 1.59 & 1.85 & 1.26 \\
\hline $\mathrm{LH}[\mathrm{mlU} / \mathrm{mL}]$ & 4.18 & 3.43 & 4.29 \\
\hline $\mathrm{FSH}[\mathrm{mlU} / \mathrm{mL}]$ & 4.23 & 2.35 & 4.57 \\
\hline Estradiol [pg/mL] & 40.09 & 13.06 & 40.72 \\
\hline $\mathrm{PRL} 0^{\prime}[\mathrm{ng} / \mathrm{mL}]$ & 19.71 & 12.2 & 16.64 \\
\hline $\mathrm{PRL} 60^{\prime}[\mathrm{ng} / \mathrm{mL}]$ & 178.54 & 87.65 & 171.2 \\
\hline $\mathrm{TSH}[\mu \mathrm{IU} / \mathrm{mL}]$ & 2.33 & 3.11 & 1.9 \\
\hline fT3 [pg/mL] & 3.17 & 0.41 & 3.08 \\
\hline fT4 [ng/dL] & 1.48 & 1.88 & 1.24 \\
\hline Baseline cortisol [ $\mu \mathrm{g} / \mathrm{dL}]$ & 16.81 & 6.51 & 15.82 \\
\hline ACTH $[\mathrm{pg} / \mathrm{mL}]$ & 32.23 & 26.48 & 24.42 \\
\hline $\begin{array}{l}\text { Cortisol-suppression test } \\
{[\mu \mathrm{g} / \mathrm{dL}]}\end{array}$ & 0.97 & 0.16 & 1.00 \\
\hline
\end{tabular}

$\mathrm{SD}$ - standard deviation; $\mathrm{BMI}$ - body mass index; $\mathrm{BMD}$ - bone mineral density; AAT — android; FAT — female; VAT — visceral; DHEAS - dehydroepiandrosterone; SHBG — sex hormone-binding globulin; FAI - free androgen index; LH - luteinizing hormone; $\mathrm{FSH}$ - follicle-stimulating hormone; PRL $0^{\prime}$ - prolactin at the baseline; PRL $60^{\prime}$ - prolactin at 60 min of metoclopramide challenge; TSH - thyroid-stimulating hormone; $\mathrm{fT} 3$ - free triiodothyronine; $\mathrm{fT} 4$ — free thyroxine; $\mathrm{ACTH}$ — adrenocorticotropic hormone

adipose tissue and VAT correlated positively with free testosterone and inversely with prolactin at $60 \mathrm{~min}$ of metoclopramide challenge (Tab. 2).

BMD in both lumbar spine and entire skeleton turned out to correlate positively with body weight and BMI of the study subjects. Also, a positive correlation was found between BMD of the entire skeleton and body height. Additionally, BMD in both the lumbar spine and entire skeleton showed inverse 
Table 2. Spearman's coefficients of rank correlation (R) between the volume of adipose tissue in various anatomical regions [ $\left.\mathrm{cm}^{3}\right]$ and bone mineral density and endocrine parameters of the study subjects

\begin{tabular}{|c|c|c|c|c|c|}
\hline \multicolumn{2}{|l|}{ Variable } & \multirow{2}{*}{$\begin{array}{c}\text { AAT } \\
0.336\end{array}$} & \multirow{2}{*}{$\begin{array}{c}\text { FAT } \\
0.345\end{array}$} & \multirow{2}{*}{$\begin{array}{c}\text { Overall fat } \\
0.331\end{array}$} & \multirow{2}{*}{$\begin{array}{c}\text { VAT } \\
0.277\end{array}$} \\
\hline DMO $145 \mathrm{r}^{2} \mathrm{~cm}$ & $\mathrm{R}$ & & & & \\
\hline DIVIU LI-L4 $\left[\mathrm{g} / \mathrm{cm}^{-1}\right.$ & $p$ & $<0.001$ & $<0.001$ & $<0.001$ & $<0.001$ \\
\hline \multirow{2}{*}{ BMD total $\left[\mathrm{g} / \mathrm{cm}^{2}\right]$} & $\mathrm{R}$ & 0.529 & 0.527 & 0.550 & 0.453 \\
\hline & $p$ & $<0.001$ & $<0.001$ & $<0.001$ & $<0.001$ \\
\hline \multirow{2}{*}{ Androstenedione $[\mathrm{ng} / \mathrm{mL}]$} & $\mathrm{R}$ & -0.022 & -0.020 & -0.050 & -0.036 \\
\hline & $p$ & 0.728 & 0.749 & 0.425 & 0.568 \\
\hline \multirow{2}{*}{ DHEA $[\mu \mathrm{g} / \mathrm{mL}]$} & $\mathrm{R}$ & 0.119 & 0.120 & 0.105 & 0.094 \\
\hline & $p$ & 0.065 & 0.061 & 0.102 & 0.148 \\
\hline \multirow{2}{*}{ Testosterone [ng/mL] } & $\mathrm{R}$ & 0.143 & 0.117 & 0.111 & 0.129 \\
\hline & $p$ & 0.021 & 0.060 & 0.074 & 0.039 \\
\hline \multirow{2}{*}{ SHBG [nmol/L] } & $\mathrm{R}$ & -0.540 & -0.435 & -0.498 & -0.533 \\
\hline & $p$ & $<0.001$ & $<0.001$ & $<0.001$ & $<0.001$ \\
\hline \multirow{2}{*}{ FAI } & $\mathrm{R}$ & 0.456 & 0.344 & 0.410 & 0.469 \\
\hline & $p$ & $<0.001$ & $<0.001$ & $<0.001$ & $<0.001$ \\
\hline \multirow{2}{*}{ 17-hydroxyprogesterone [ng/mL] } & $\mathrm{R}$ & -0.042 & -0.003 & -0.021 & -0.034 \\
\hline & $p$ & 0.641 & 0.970 & 0.817 & 0.709 \\
\hline \multirow{2}{*}{$\mathrm{LH}[\mathrm{mlU} / \mathrm{mL}]$} & $\mathrm{R}$ & 0.055 & 0.007 & 0.043 & 0.046 \\
\hline & $\mathrm{p}$ & 0.397 & 0.911 & 0.512 & 0.481 \\
\hline \multirow{2}{*}{$\mathrm{FSH}[\mathrm{mlU} / \mathrm{mL}]$} & $\mathrm{R}$ & -0.048 & -0.012 & -0.023 & -0.046 \\
\hline & $\mathrm{p}$ & 0.446 & 0.848 & 0.710 & 0.465 \\
\hline \multirow{2}{*}{ Estradiol [pg/mL] } & $\mathrm{R}$ & 0.037 & 0.006 & 0.010 & 0.060 \\
\hline & $\mathrm{p}$ & 0.556 & 0.919 & 0.873 & 0.345 \\
\hline \multirow{2}{*}{ PRL0' $[\mathrm{ng} / \mathrm{mL}]$} & $\mathrm{R}$ & 0.210 & 0.140 & 0.179 & 0.187 \\
\hline & $\mathrm{p}$ & 0.001 & 0.027 & 0.004 & 0.003 \\
\hline \multirow{2}{*}{ PRL60' $[\mathrm{ng} / \mathrm{mL}]$} & $\mathrm{R}$ & -0.169 & -0.143 & -0.158 & -0.160 \\
\hline & $\mathrm{p}$ & 0.038 & 0.079 & 0.051 & 0.049 \\
\hline \multirow{2}{*}{$\mathrm{TSH}[\mu \mathrm{IU} / \mathrm{mL}]$} & $\mathrm{R}$ & 0.170 & 0.142 & 0.170 & 0.163 \\
\hline & $\mathrm{p}$ & 0.007 & 0.025 & 0.007 & 0.010 \\
\hline \multirow{2}{*}{$\mathrm{fT} 3[\mathrm{pg} / \mathrm{mL}]$} & $\mathrm{R}$ & 0.193 & 0.080 & 0.130 & 0.149 \\
\hline & $p$ & 0.113 & 0.516 & 0.286 & 0.222 \\
\hline \multirow{2}{*}{ fT4 [ng/dL] } & $\mathrm{R}$ & -0.068 & -0.031 & -0.044 & -0.068 \\
\hline & $\mathrm{p}$ & 0.302 & 0.637 & 0.505 & 0.304 \\
\hline \multirow{2}{*}{ Baseline cortisol [ng/dL] } & $\mathrm{R}$ & -0.092 & -0.136 & -0.120 & -0.101 \\
\hline & $p$ & 0.291 & 0.115 & 0.166 & 0.245 \\
\hline \multirow{2}{*}{ ACTH $[p g / m L]$} & $\mathrm{R}$ & 0.018 & -0.041 & -0.020 & 0.025 \\
\hline & $\mathrm{p}$ & 0.837 & 0.646 & 0.820 & 0.783 \\
\hline
\end{tabular}

BMD — bone mineral density; AAT — android; FAT — female; VAT — visceral; DHEA — dehydroepiandrosterone; SHBG — sex hormone-binding globulin; FAI — free androgen index; LH - luteinizing hormone; FSH — follicle-stimulating hormone; PRL $0^{\prime}$ - prolactin at the baseline; PRL $60^{\prime}$ - prolactin at 60 min of metoclopramide challenge; $\mathrm{TSH}$ - thyroid-stimulating hormone; $\mathrm{fT} 3$ — free triiodothyronine; $\mathrm{fT} 4$ — free thyroxine; $\mathrm{ACTH}$ — adrenocorticotropic hormone

association with SHBG and correlated positively with FAI. Furthermore, positive correlations were found between BMD in the lumbar spine and estra- diol, and between BMD in the entire skeleton and cortisol level after suppression with dexamethasone (Tab. 3). 
Table 3. Spearman's coefficients of rank correlation (R) between bone mineral density, age, anthropometric and endocrine parameters of the study subjects

\begin{tabular}{|c|c|c|c|}
\hline \multicolumn{2}{|l|}{ Variable } & $\begin{array}{c}\mathrm{BMD} \text { L2-L4 } \\
{\left[\mathrm{g} / \mathrm{cm}^{2}\right]}\end{array}$ & $\begin{array}{c}\text { BMD total } \\
{\left[\mathrm{g} / \mathrm{cm}^{2}\right]}\end{array}$ \\
\hline \multirow{2}{*}{ Age (years] } & $\mathrm{R}$ & 0.064 & -0.024 \\
\hline & $\mathrm{p}$ & 0.279 & 0.691 \\
\hline \multirow{2}{*}{ Body height [cm] } & $\mathrm{R}$ & 0.116 & 0.122 \\
\hline & $\mathrm{p}$ & 0.052 & 0.041 \\
\hline \multirow{2}{*}{ Body weight [kg] } & $\mathrm{R}$ & 0.401 & 0.634 \\
\hline & $\mathrm{p}$ & $<0.001$ & $<0.001$ \\
\hline \multirow{2}{*}{ BMI $\left[\mathrm{kg} / \mathrm{m}^{2}\right]$} & $\mathrm{R}$ & 0.380 & 0.599 \\
\hline & $\mathrm{p}$ & $<0.001$ & $<0.001$ \\
\hline \multirow{2}{*}{$\begin{array}{l}\text { Androstenedione } \\
{[\mathrm{ng} / \mathrm{mL}]}\end{array}$} & $\mathrm{R}$ & -0.055 & -0.079 \\
\hline & $\mathrm{p}$ & 0.372 & 0.203 \\
\hline \multirow{2}{*}{ DHEA $[\mu \mathrm{g} / \mathrm{mL}]$} & $\mathrm{R}$ & 0.088 & 0.083 \\
\hline & $\mathrm{p}$ & 0.167 & 0.200 \\
\hline \multirow{2}{*}{ Testosterone [ng/mL] } & $\mathrm{R}$ & 0.065 & 0.089 \\
\hline & $\mathrm{p}$ & 0.295 & 0.153 \\
\hline \multirow{2}{*}{ SHBG [nmol/L] } & $\mathrm{R}$ & -0.191 & -0.326 \\
\hline & $p$ & $<0.001$ & $<0.001$ \\
\hline \multirow{2}{*}{ FAI } & $\mathrm{R}$ & 0.150 & 0.279 \\
\hline & $p$ & 0.037 & $<0.001$ \\
\hline \multirow{2}{*}{$\begin{array}{l}\text { 17-hydroxyprogesterone } \\
{[\mathrm{ng} / \mathrm{mL}]}\end{array}$} & $\mathrm{R}$ & 0.043 & 0.014 \\
\hline & $\mathrm{p}$ & 0.632 & 0.878 \\
\hline \multirow{2}{*}{$\mathrm{LH}[\mathrm{mlU} / \mathrm{mL}]$} & $\mathrm{R}$ & -0.065 & 0.000 \\
\hline & $\mathrm{p}$ & 0.315 & 0.998 \\
\hline \multirow{2}{*}{$\mathrm{FSH}[\mathrm{mIU} / \mathrm{mL}]$} & $\mathrm{R}$ & -0.064 & -0.060 \\
\hline & $\mathrm{p}$ & 0.300 & 0.337 \\
\hline \multirow{2}{*}{ Estradiol [pg/mL] } & $\mathrm{R}$ & 0.156 & 0.059 \\
\hline & $\mathrm{p}$ & 0.013 & 0.350 \\
\hline \multirow{2}{*}{ PRL $0^{\prime}[\mathrm{ng} / \mathrm{mL}]$} & $\mathrm{R}$ & 0.090 & 0.113 \\
\hline & $\mathrm{p}$ & 0.154 & 0.075 \\
\hline \multirow{2}{*}{$\mathrm{PRL} 60^{\prime}[\mathrm{ng} / \mathrm{mL}]$} & $\mathrm{R}$ & 0.006 & -0.074 \\
\hline & $p$ & 0.942 & 0.362 \\
\hline \multirow{2}{*}{$\mathrm{TSH}[\mu \mathrm{IU} / \mathrm{mL}]$} & $\mathrm{R}$ & -0.060 & 0.035 \\
\hline & $p$ & 0.347 & 0.584 \\
\hline \multirow{2}{*}{ fT3 [pg/mL] } & $\mathrm{R}$ & 0.029 & 0.052 \\
\hline & $\mathrm{p}$ & 0.810 & 0.669 \\
\hline \multirow{2}{*}{ fT4 [ng/dL] } & $\mathrm{R}$ & 0.077 & -0.038 \\
\hline & $p$ & 0.244 & 0.565 \\
\hline \multirow{2}{*}{ Baseline cortisol [ $\mu \mathrm{g} / \mathrm{dL}]$} & $\mathrm{R}$ & 0.066 & -0.017 \\
\hline & $p$ & 0.443 & 0.841 \\
\hline \multirow{2}{*}{ ACTH $[p g / m L]$} & $\mathrm{R}$ & 0.067 & 0.136 \\
\hline & $p$ & 0.445 & 0.126 \\
\hline
\end{tabular}

$\mathrm{BMI}$ - body mass index; BMD - bone mineral density; DHEA

- dehydroepiandrosterone; SHBG — sex hormone-binding globulin; FAI — free androgen index; $\mathrm{LH}$ - luteinizing hormone; $\mathrm{FSH}$ - follicle-stimulating hormone; PRL $0^{\prime}$ - prolactin at the baseline; PRL $60^{\prime}$ - prolactin at 60 min of metoclopramide challenge; $\mathrm{TSH}$ - thyroid-stimulating hormone; $\mathrm{fT} 3$ - free triiodothyronine; fT4 - free thyroxine; ACTH — adrenocorticotropic hormone
Multiple regression analysis, including all the significant correlates of BMD mentioned above, did not identify any independent predictors of this parameter in women with functional menstrual dysfunction, either for the lumbar spine or for the entire skeleton.

\section{DISCUSSION}

Secondary amenorrhea is defined as the absence of menstruation for a period of three months in a non-pregnant woman who previously had regular menstrual periods. A common reason for secondary amenorrhea is FHA which is associated with functional inhibition of the hypothalamic-pituitary-ovarian axis without a presence of organic disease. Although FHA is usually diagnosed only after other known causes of amenorrhea have been ruled out, $\mathrm{FSH}$ and LH concentrations below $5 \mathrm{U} / \mathrm{L}$ are often listed among its diagnostics criteria $[1,12]$. We also proved that the use of these determinations are useful in women with functional menstrual disorders, in whom levels of either FSH or LH were mostly below the lower cut-off. However, it is believed that initial stage of FHA may be also caused by discrete neuroendocrine disturbances that may not have yet appeared in hormonal tests [12]. Still, the pathogenesis of these condition is not fully understood. Multiple hormones, neuropeptides and neurosteroids disorders have been found. It seems that mediators involved in stress response, hunger and satiety regulation are particularly important in the pathomechanism of this disease: leptin, ghrelin, $\beta$-endorphins, serotonin, neuropeptide $Y(N P Y)$, corticoliberin $(\mathrm{CRH})$, catecholamines and many others [13]. This type of amenorrhea, through a cascade of relationships in the cerebral-hypothalamic-pituitary-ovarian axis, results directly from estrogen deficiency, which may have an adverse effect on peak bone mass achieved by young women. In this paper we investigated the relationship between volume of adipose tissue and its distribution and the bone mineral density.

In our study, volume of adipose tissue, both overall and in all analyzed anatomical regions, correlated positively with BMD of investigated women. As mentioned previously, recent evidence suggests that such relationship is true solely for subcutaneous fat $[7,8]$, there seems to be an inverse correlation between VAT and BMD [8-10]. Consequently, our findings may be considered surprising. However, it should be remembered that we examined patients with functional menstrual disorders, namely a group in which certain neuroendocrine mechanisms had already to be disturbed and some hypothalamic and even 
an ovarian insufficiency could have already occurred [1]. Ovarian insufficiency is an established risk factor for both BMD deficiency and metabolic disorders [13]. Therefore, we studied a link between the distribution of body fat and endocrine parameters as well.

As already mentioned, ovarian insufficiency results in a relative excess of androgens over estrogens. Our findings imply that this may also interfere with the accumulation of adipose tissue. SHBG is a key regulator of free androgen concentration [14], and previous studies demonstrated that its level correlates inversely with body weight $[15,16]$. Furthermore, women with central obesity were shown to synthesize more androgens than those with peripheral accumulation of body fat [17]. This may explain why the volumes of android adipose tissue and VAT in our patients correlated positively with free testosterone and FAl and showed inverse correlations with SHBG. However, it should be remembered that similar relationships with SHBG and FAI were also found for female adipose tissue volume. Perhaps, this phenomenon reflected a loss of differences in the lipolytic activity of subcutaneous fat and VAT in women with menstrual disorders.

Like previous studies of obese and normal-weight women [18-20], we found positive correlations between TSH and adipose tissue volume. According to literature, this association may be mediated by leptin, as also concentration of this adipokine was shown to correlate positively with TSH level [18].

We also observed positive correlations between adipose tissue volumes in all analyzed regions and baseline concentration of prolactin. However, concentration of this hormone at $60 \mathrm{~min}$ of metoclopramide challenge correlated inversely with the volumes of android and visceral fat. Available literature provides an explanation for these seemingly contradictive findings. Under physiological conditions, prolactin is synthesized mainly in the pituitary gland. However, a local synthesis of this hormone in adipose tissue was demonstrated recently as well [21], which would explain the hereby documented positive correlation between concentration of prolactin at the baseline and body adiposity. If pituitary glands were the principal source of prolactin in our patients, also its level measured after administration of metoclopramide would correlate positively with adipose tissue volume. However, the hereby documented inverse correlation between these parameters implies that an increase in body adiposity (and resultant hyperinsulinemia) contributed to impaired synthesis of prolactin in the pituitary gland; similar associations were already reported by other authors $[22,23]$.
The positive correlation between BMD in the lumbar spine and concentration of estradiol in our patients is not surprising, since as already mentioned, estrogen deficiency is an established risk factor for bone loss [2-4]. Also, the inverse correlation between BMD and SHBG can be explained in light of the results of previous studies [24-26]. Preferential bonding of androgens to SHBG and subsequent reduction of conversion to estrogens would explain not only the inverse correlation between concentration of this globulin and BMD, but also positive associations between bone density and FAI. Review of published evidence enabled us also to identify the most plausible reason behind the positive correlation between BMD and concentration of cortisol during dexamethasone suppression test. Positive result of this test reflects overproduction of $\mathrm{ACHT}$, a hormone exerting anabolic effects in the bone [27].

During the last stage of our study, we have conducted a multivariate regression analysis to explain complex relationships between the volume and distribution of adipose tissue, endocrine parameters and BMD in women with menstrual disorders. However, we did not identify any independent determinants of BMD and discriminative power of the regression models was very low. This confirms than BMD is a product of many factors, including at least few that have not been analyzed in this study, e.g., diet and physical activity. Furthermore, the lack of independent predictors for BMD points to potential presence of interrelationships between analyzed explanatory variables.

\section{Clinical implications}

Our study confirmed that women with ovarian insufficiency and excessive content of adipose tissue, irrespective of its distribution, are at increased risk of bone mass deficiency. Therefore, patients with menstrual disorders should be covered with complex programs of secondary prevention, including dietary counseling, lifestyle modification, regular general medical, cardiological, endocrinological and densitometric checkups. Furthermore, this study confirmed lack of a single accurate marker for individual risk assessment of BMD depletion in patients with menstrual disorders. We also showed that DEXA-based analysis of adipose tissue distribution has probably limited clinical application in this group of patients.

\section{Study limitations}

The most important limiting factor for this study is its retrospective nature, so we were not able either to analyze the effects of potential confounders 
on BMD or to determine additional laboratory parameters, such as concentrations of adipokines and proinflammatory cytokines. Furthermore, the study group was quite heterogenous and included women with menstrual disorders of various etiology. Due to the large size of the study group and selecting of statistical methodology (analysis of correlation and regression, rather than intergroup comparisons) we believe that the hereby presented findings are reliable; this assumption appears to be supported by their vital coherence with published data.

\section{CONCLUSIONS}

BMD in women with menstrual disorders is determined by a plethora of interrelated metabolic and endocrine mechanisms. Volume of body fat is only one of numerous determinants of BMD in women with hypothalamic ovarian insufficiency and therefore, should not be taken as the only risk factor for bone mass deficiency. Due to changed metabolic and hormonal profile of women with psychogenic hypothalamic amenorrhea, the functional differences between subcutaneous and visceral fat appear to blur in this group. As a result, determining the distribution of adipose tissue in patients with ovarian failure is likely to be of less clinical importance.

\section{Conflict of interest}

The authors state that there are no conflicts of interest to disclose.

\section{REFERENCES}

1. Gordon CM. Functional hypothalamic amenorrhea. N Engl J Med. 2010; 363(4): 365-371, doi: 10.1056/NEJMcp0912024, indexed in Pubmed: 20660404.

2. Joy EA, Campbell D. Stress fractures in the female athlete. Curr Sports Med Rep. 2005; 4(6):323-328, doi: 10.1097/01.csmr.0000306294.72578. a8, indexed in Pubmed: 16282034.

3. Riggs BL. The mechanisms of estrogen regulation of bone resorption. J Clin Invest. 2000; 106(10): 1203-1204, doi: 10.1172/JCl11468, indexed in Pubmed: 11086020.

4. Valentino R, Savastano S, Tommaselli AP, et al. The influence of intense ballet training on trabecular bone mass, hormone status, and gonadotropin structure in young women. J Clin Endocrinol Metab. 2001; 86(10): 4674-4678, doi: 10.1210/jcem.86.10.7908, indexed in Pubmed: 11600524.

5. Vanderschueren D, Vandenput L, Boonen S, et al. Androgens and bone. Endocr Rev. 2004; 25(3): 389-425, doi: 10.1210/er.2003-0003, indexed in Pubmed: 15180950.

6. Siemińska L. Adipose tissue. Pathophysiology, distribution, sex differences and the role in inflammation and cancerogenesis. Endokrynol Pol. 2007; 58(4): 330-342, indexed in Pubmed: 18058725.

7. Deere K, Sayers A, Viljakainen HT, et al. Distinct relationships of intramuscular and subcutaneous fat with cortical bone: findings from a cross-sectional study of young adult males and females. J Clin Endocrinol Metab. 2013; 98(6): E1041-E1049, doi: 10.1210/jc.2013-1272, indexed in Pubmed: 23533224.

8. Gilsanz V, Chalfant J, Mo AO, et al. Reciprocal relations of subcutaneous and visceral fat to bone structure and strength. J Clin Endocrinol Metab. 2009; 94(9): 3387-3393, doi: 10.1210/jc.2008-2422, indexed in Pubmed: 19531595.
9. Bredella MA, Torriani M, Ghomi RH, et al. Vertebral bone marrow fat is positively associated with visceral fat and inversely associated with IGF-1 in obese women. Obesity (Silver Spring). 2011; 19(1): 49-53, doi: 10.1038/oby.2010.106, indexed in Pubmed: 20467419.

10. Russell M, Mendes N, Miller KK, et al. Visceral fat is a negative predictor of bone density measures in obese adolescent girls. J Clin Endocrinol Metab. 2010; 95(3): 1247-1255, doi: 10.1210/jc.2009-1475, indexed in Pubmed: 20080853.

11. Singhal V, Maffazioli GDN, Cano Sokoloff N, et al. Regional fat depots and their relationship to bone density and microarchitecture in young oligo-amenorrheic athletes. Bone. 2015; 77: 83-90, doi: 10.1016/j. bone.2015.04.005, indexed in Pubmed: 25868796.

12. Genazzani AD, Ricchieri F, Lanzoni $C$, et al. Diagnostic and therapeutic approach to hypothalamic amenorrhea. Ann NY Acad Sci. 2006; 1092: 103-113, doi: 10.1196/annals.1365.009, indexed in Pubmed: 17308137.

13. Sowińska-Przepiera E, Andrysiak-Mamos E, Jarząbek-Bielecka G, et al. Functional hypothalamic amenorrhea - diagnostic challenges, monitoring and treatment. Endokrynologia Polska. 2015; 66(3): 252-268, doi: 10.5603/ep.2015.0033.

14. Pasquali R. Obesity and androgens: facts and perspectives. Fertil Steril. 2006; 85(5): 1319-1340, doi: 10.1016/j.fertnstert.2005.10.054, indexed in Pubmed: 16647374.

15. Pasquali $R$, Casimirri F, Platè $L$, et al. Characterization of obese women with reduced sex hormone-binding globulin concentrations. Horm Metab Res. 1990; 22(5): 303-306, doi: 10.1055/s-2007-1004907, indexed in Pubmed: 2189819.

16. Tchernof A, Després JP. Sex steroid hormones, sex hormone-binding globulin, and obesity in men and women. Horm Metab Res. 2000; 32(11-12): 526-536, doi: 10.1055/s-2007-978681, indexed in Pubmed: 11246820.

17. Kirschner MA, SamojlikE, Drejka M, et al. Androgen-estrogen metabolism in women with upper body versus lower body obesity. J Clin Endocrinol Metab. 1990; 70(2): 473-479, doi: 10.1210/jcem-70-2-473, indexed in Pubmed: 2298859.

18. lacobellis G, Ribaudo MC, Zappaterreno A, et al. Relationship of thyroid function with body mass index, leptin, insulin sensitivity and adiponectin in euthyroid obese women. Clin Endocrinol (Oxf). 2005; 62(4): 487-491, doi: 10.1111/j.1365-2265.2005.02247.x, indexed in Pubmed: 15807881.

19. Nannipieri $M$, Cecchetti $F$, Anselmino $M$, et al. Expression of thyrotropin and thyroid hormone receptors in adipose tissue of patients with morbid obesity and/or type 2 diabetes: effects of weight loss. Int J Obes (Lond). 2009; 33(9): 1001-1006, doi: 10.1038/ijo.2009.140, indexed in Pubmed: 19636322

20. Radetti G, Kleon W, Buzi F, et al. Thyroid function and structure are affected in childhood obesity. J Clin Endocrinol Metab. 2008; 93(12): 4749-4754, doi: 10.1210/jc.2008-0823, indexed in Pubmed: 18840640.

21. Pala NA, Laway BA, Misgar RA, et al. Profile of leptin, adiponectin, and body fat in patients with hyperprolactinemia: Response to treatment with cabergoline. Indian J Endocrinol Metab. 2016; 20(2): 177-181, doi: 10.4103/2230-8210.176346, indexed in Pubmed: 27042412.

22. Kopelman PG, Weaver JU, Noonan K, et al. Impaired hypothalamic control of prolactin secretion in massive obesity. Lancet. 1979; 313(8119): 747750, doi: 10.1016/s0140-6736(79)91206-6, indexed in Pubmed: 85990.

23. Weaver JU, Noonan K, Kopelman PG, et al. Impaired prolactin secretion and body fat distribution in obesity. Clin Endocrinol (Oxf). 1990; 32(5): 641-646, doi: 10.1111/j.1365-2265.1990.tb00908.x, indexed in Pubmed: 2194712.

24. Bjørnerem A, Emaus N, Berntsen GKR, et al. Circulating sex steroids, sex hormone-binding globulin, and longitudinal changes in forearm bone mineral density in postmenopausal women and men: the Troms $\varnothing$ study. Calcif Tissue Int. 2007; 81(2): 65-72, doi: 10.1007/s00223-007-9035-z, indexed in Pubmed: 17612780.

25. Ooms ME, Lips P, Roos JC, et al. Vitamin D status and sex hormone binding globulin: determinants of bone turnover and bone mineral density in elderly women. J Bone Miner Res. 1995; 10(8): 1177-1184, doi: 10.1002/jbmr.5650100806, indexed in Pubmed: 8585420.

26. Rapuri PB, Gallagher JC, Haynatzki G. Endogenous levels of serum estradiol and sex hormone binding globulin determine bone mineral density, bone remodeling, the rate of bone loss, and response to treatment with estrogen in elderly women. J Clin Endocrinol Metab. 2004; 89(10): 4954-4962, doi: 10.1210/jc.2004-0434, indexed in Pubmed: 15472191.

27. Isales CM, Zaidi M, Blair HC. ACTH is a novel regulator of bone mass. Ann NYAcad Sci. 2010; 1192: 110-116, doi: 10.1111/j.1749-6632.2009.05231.x, indexed in Pubmed: 20392225. 